\title{
ATMOSPHERIC WEIGHTED MEAN TEMPERATURE MODEL IN GUILIN
}

\author{
Mo Zhixiang ${ }^{1}$, Huang Liangke ${ }^{1,2}$ *, Peng Hua ${ }^{1}$, Liu Lilong ${ }^{1,2}$, Kang Chuanli ${ }^{1,2}$ \\ ${ }^{1}$ College of Geomatics Engineering and Geoinformation, Guilin University of Technology, Guilin 541004, China \\ ${ }^{2}$ Guangxi Key Laboratory of Spatial Information and Geomatics, Guilin 541004, China
}

KEY WORDS: Weighted Mean Temperature, Global Navigation Satellite System, Precipitable Water Vapor, Radiosonde, Regression Analysis, Regional Model

\begin{abstract}
:
Atmospheric water vapor is an important part of the earth's atmosphere, and it has a great relationship with the formation of precipitation and climate change. In CNSS-derived precipitable water vapor (PWV), atmospheric weighted mean temperature, $T_{\mathrm{m}}$, is the key factor in the progress of retrieving PWV. In this study, using the profiles of Guilin radiosonde station in 2017, the spatiotemporal variation characteristics and relationships between $T_{\mathrm{m}}$ and surface temperature $\left(T_{\mathrm{s}}\right)$ are analyzed in Guilin, an empirical $T_{\mathrm{m}}$ model suitable for Guilin is constructed by regression analysis. Comparing the $T_{\mathrm{m}}$ values calculated from Bevis model, Li Jianguo model and new model, it is found that the root mean square error (RMSE) of new model is $2.349 \mathrm{~K}$, which are decreased by $14 \%$ and $19 \%$, respectively. Investigating the impact of different $T_{\mathrm{m}}$ models on GNSS-PWV, the $T_{\mathrm{m}}$-induced error from new model has a smaller impact on PWV than other two models. The results show that the new $T_{\mathrm{m}}$ model in Guilin has a relatively good performance and it can improve the reliability of the regional GNSS water vapor retrieval to some extent.
\end{abstract}

\section{INTRODUCTION}

Water vapor, an important factor in the formation and evolution of disastrous weather, its change are the main driving force of weather and climate change. One of the basic problems of meteorology and weather forecast is to accurately measure the release and change of atmospheric water vapor (Li, 2014). Over the past few decades, many techniques have been developed to detect water vapor, including radiosondes, Global Positioning System (GPS) receivers, microwave radiometers, multifilter rotating shadowband radiometer, Raman radar, satellite remote sensing, and ground-based sun photometry (Xie et al., 2017). Among them, radiosonde is the main PWV measurement technology nowadays. But due to its high cost, low temporal and spatial resolution (only two observations are made a day), there is still a big gap between the requirements of monitoring and forecasting severe weather at medium and small scales. With the development of Global Navigation Satellite System (GNSS), a reliable and common technique to retrieve precipitable water vapor (PWV) is the ground-based GNSS, which can detect earth's atmospheric propagation delay and further estimate the PWV. GNSS meteorology has attracted much attention recently because of its low cost, applicability to all weather, high temporal resolution and level of accuracy within 1-2 mm (Elgered et al., 1997; Emardson et al., 1998; Hernández-Pajares et al., 2001; Bokoye et al., 2003; VaqueroMartínez et al., 2017). In ground-based GNSS, the idea of retrieving PWV is to obtain the zenith wet delay (ZWD) and the water vapor conversion factor ( $\Pi), T_{\mathrm{m}}$ is the key parameter of $\Pi$, hence, estimating $T_{\mathrm{m}}$ precisely is an important guarantee to improve the accuracy of PWV calculation and accomplish realtime PWV estimate.

There are lots of researchers having done a lot of study work with the atmospheric weighted mean temperature $\left(T_{\mathrm{m}}\right)$ for a more effective calculation of GNSS PWV. Bevis et al. (Bevis et al., 1992) found that $T_{\mathrm{m}}$ and surface temperature $\left(T_{\mathrm{s}}\right)$ have a good linear correlation using 8718 radiosonde profiles in North America, and proposed an empirical formula which is a commonly used model to estimate $T_{\mathrm{m}}$. Some regional linear functions of $T_{\mathrm{m}}$ and $T_{\mathrm{s}}$ were established in China. $\mathrm{Li}$ et al .(Li et al., 1999) used mesoscale meteorological model to fit out the linear regression equation of $T_{\mathrm{m}}$ and $T_{\mathrm{s}}$ in eastern China by using the radiosonde profiles of eastern China $\left(20^{\circ} \sim 50^{\circ} \mathrm{N}\right.$, $100^{\circ} \sim 130^{\circ} \mathrm{E}$ ) in 1992 . Liu et al. (Liu et al., 2012) presented three strategies for establishing the regional empirical $T_{\mathrm{m}}$ model in Guangxi and the proposed regional Hybrid model is higher than that of the well-known Bevis formula and of some other existing models and can reach an accuracy within $1 \mathrm{~mm}$ for the CPS-derived PWV estimates for the applied region.

In this paper, a regional empirical $T_{\mathrm{m}}$ model suitable for Guilin is constructed by using the radiosonde profiles of Guilin in 2017.

\section{METHODS AND DATA SOURCE}

\section{$2.1 T_{\mathrm{m}}$ Calculation}

The basic formula of PWV retrieves from GNSS as follows (Askne et al., 1987):

$$
\mathrm{PWV}=\Pi \cdot \mathrm{ZWD}
$$

Where $\Pi$ is the dimensionless atmospheric conversion factor, and ZWD is the zenith wet delay.

According to the radiosonde profiles and the observation data of surface temperature, the local atmospheric weighted mean temperature $\left(T_{\mathrm{m}}\right)$ empirical model is obtained by regression statistical method, and then based on the good linear relationship between the $T_{\mathrm{m}}$ and $T_{\mathrm{s}}$, the regression analysis method is used to assume the form of the regression equation as follows (Bevis et al., 1992):

\footnotetext{
* Corresponding author: lkhuang666@163.com
} 


$$
T_{m}=a+b \cdot T_{s}
$$

Where $a$ and $b$ are the coefficients of regression equation, they both can be calculated using the principle of least squares in statistics with years of radiosonde profiles. The $T_{\mathrm{m}}$ values can be easily calculated by taking into the $T_{\mathrm{s}}$ values where provided by radiosonde profiles. Nowadays, Bevis model is the common and reliable empirical model (Bevis et al., 1992):

$$
T_{m}=70.2+0.72 T_{s}
$$

In addition, $\mathrm{Li}$ et al. ( $\mathrm{Li}$ et al., 1999) established a model using local radiosonde profiles in eastern China for local use:

$$
T_{m}=44.05+0.81 T_{s}
$$

According to the $T_{\mathrm{m}}$ value, the $\Pi$ can be calculated by the following equation :

$$
\Pi=\frac{10^{6}}{\rho_{w} R_{v}\left[\left(k_{3} / T_{m}+k_{2}^{\prime}\right)\right]}
$$

Where $\rho_{w}$ is the density of liquid water $\left(1 \times 10^{3} \mathrm{~kg} / \mathrm{m}^{3}\right) . R_{v}$ is the vapor gas constant $\left(461.495 \mathrm{~J} \cdot \mathrm{kg}^{-1} \cdot \mathrm{k}^{-1}\right) . k_{2}^{\prime}$ and $k_{3}$ are the atmospheric physical parameters, and the empirical values are usually $22.13 \pm 2.20 \mathrm{~K} / \mathrm{hPa}$ and $(3.739 \pm 0.012 \mathrm{~K} / \mathrm{hPa})$, respectively.

\subsection{Data Sources}

\begin{tabular}{|c|c|c|c|}
\hline Stations & 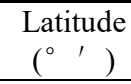 & $\begin{array}{c}\text { Longitude } \\
\left(\begin{array}{c}0 \\
(\end{array}\right)\end{array}$ & $\begin{array}{c}\text { Elevation } \\
(\mathrm{m})\end{array}$ \\
\hline Radiosonde & $25^{\circ} 19^{\prime}$ & $110^{\circ} 18^{\prime}$ & 164.4 \\
\hline
\end{tabular}

In this paper, the Guilin radiosonde profiles in 2017 are selected to establish $T_{\mathrm{m}}$ model in Guilin. The location information of radiosonde station in Guilin is shown in Table 1.

Table 1. The information of Guilin radiosonde station

The Guilin radiosonde profiles can be directly downloaded from the upper-air archive at the website of the University of Wyoming (http://www.weather.uwyo.edu/upperair/sounding.ht$\mathrm{ml}$ ). The radiosonde profiles include atmospheric stratification data detected by sounding balloon at UTC 00: 00 and 12: 00 twice a day, including surface parameters such as $T_{\mathrm{s}}, P_{\mathrm{s}}$, PWV and pressure level parameters such as geopotential height $(H)$, relative humidity $(\mathrm{RH})$ and absolute temperature $(T)$ at every pressure level, and the location information of the radiosonde station is also provided. According to different surfaces, the $T_{\mathrm{m}}$ values are calculated by numerical integration method. The formula to calculate $T_{\mathrm{m}}$ can be expressed as follows:

$$
T_{m}=\frac{\int_{h s}^{\infty}(e / T) d z}{\int_{h s}^{\infty}\left(e / T^{2}\right) d z}
$$

Where $e$ and $T$ are the water vapor pressure (unit: $\mathrm{hPa}$ ) and absolute temperature (unit: $\mathrm{K}$ ), respectively; $h_{\mathrm{s}}$ is the geodetic height of the measuring station (unit: $\mathrm{m}$ ). Generally, the $e$ is not directly provided in radiosonde profiles. However, it can be calculated by the following formula (Bolton et al., 1980; Wang et al., 2016):

$$
\begin{aligned}
& e=\frac{R H \cdot e_{s}}{100} \\
& e_{s}=6.112 \times 10^{\left(\frac{7.5 \times T d}{T d+273.3}\right)}
\end{aligned}
$$

Where $e_{\mathrm{s}}$ is the saturated vapor pressure (unit: $\mathrm{hPa}$ ) and $T_{\mathrm{d}}$ is the atmospheric temperature in Celsius $\left(T=T_{\mathrm{d}}+273.15\right)$. In practice, Equation (8) will be discretized using the following integral formula:

$$
T_{m}=\frac{\int_{h_{s}}^{\infty}(e / T) d z}{\int_{h_{s}}^{\infty}\left(e / T^{2}\right) d z}=\frac{\sum_{1}^{n} \psi\left(e_{i}, T_{i}\right) \Delta h_{i}}{\sum_{1}^{n} \phi\left(e_{i}, T_{i}\right) \Delta h_{i}}
$$

Where $\psi\left(e_{i}, T_{i}\right)=\frac{e_{i}}{T_{i}}, \phi\left(e_{i}, T_{i}\right)=\frac{e_{i}}{T_{i}^{2}} ; \Delta h_{i}$ indicates the thickness of the atmosphere at the $i$ th layer (unit: $\mathrm{m}$ ), $n$ is the number of layers; and $T_{\mathrm{i}}$ and $e_{i}$ indicate the average temperature and water vapor pressure at the $i$ th layer of the atmosphere, respectively.

\section{RESULTS}

\subsection{Establishment of $T_{\mathrm{m}}$ Model in Guilin}

In order to minimize the $T_{\mathrm{m}}$ calculation error and improve the accuracy of GNSS water vapor, it is necessary to use radiosonde profiles to establish the local $T_{\mathrm{m}}$ empirical model applicable to Guilin.

After preliminary data processing, 723 data samples are obtained. According to numerical integration method, the $T_{\mathrm{m}}$ values are calculated, and the $T_{\mathrm{s}}$ values are obtained from radiosonde data. Before the establishment of $T_{\mathrm{m}}$ Guilin model, it is necessary to analyze the spatial and temporal variation characteristics of $T_{\mathrm{m}}$ and $T_{\mathrm{s}}$, and the results are shown in Figure 1.

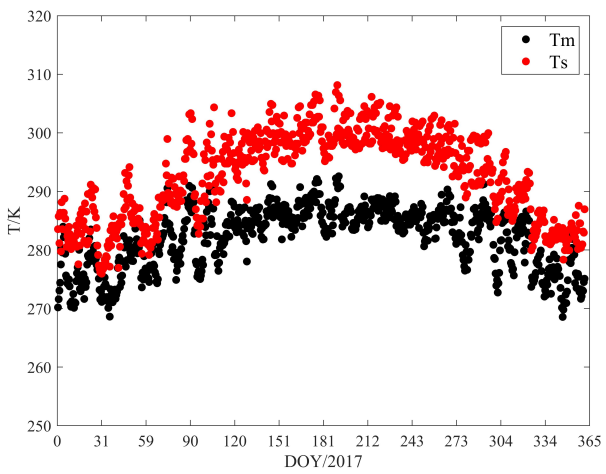

Figure 1. Time-space variation scatter plots of $T_{\mathrm{m}}$ and $T_{\mathrm{s}}$

According to the preliminary statistical analysis of the calculated data, the $T_{\mathrm{m}}$ average value of Guilin radiosonde station in 2017 is $282.063 \mathrm{~K}$, the average value of $T_{\mathrm{s}}$ is 292.576 $\mathrm{K}$. The variation of $T_{\mathrm{m}}$ and $T_{\mathrm{s}}$ with time shows a single peak curve and they have the similar trends where can be seen in Figure 1 . The $T_{\mathrm{m}}$ and $T_{\mathrm{s}}$ values increase gradually from Jan to July, and reach the maximum in summer, then began to decline since Mid-July, finally reach the minimize in winter. On the whole, the four seasons change significantly. In addition, the $T_{\mathrm{m}}$ values are lower than the $T_{\mathrm{s}}$ values, and the difference between 
them in summer obviously larger than in other seasons, and the difference in winter is the smallest.

To further analyze the functional relationship between $T_{\mathrm{m}}$ and $T_{\mathrm{s}}$ scatter diagram of $T_{\mathrm{m}}$ and $T_{\mathrm{s}}$ is drawn as shown in Figure 2 . Meanwhile, linear regression method is adopted to fit the trend line according to the principle of least square method.

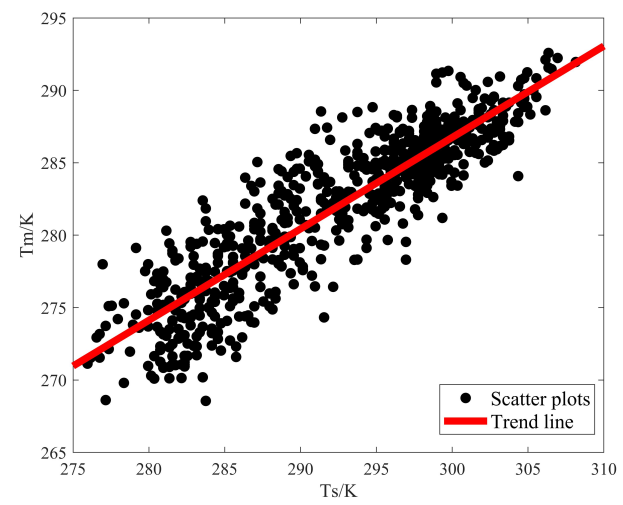

Figure 2. Scatter plots and trend line of $T_{\mathrm{m}}$ and $T_{\mathrm{s}}$

It can be seen from the Figure 2, as the surface temperature rises, the weighted average temperature also rises, and the variation trend of them is the same, and the scatter points are roughly evenly distributed above and below the trend line. Thus, it can be inferred that there is a good linear correspondence between $T_{\mathrm{m}}$ and $T_{\mathrm{s}}$. The correlation coefficient (R) of $T_{\mathrm{m}}$ and $T_{\mathrm{s}}$ is 0.8946 , bigger than 0.7 and less than 1 , indicating a strong linear relationship. Therefore, $T_{\mathrm{m}}$ and $T_{\mathrm{s}}$ have a strong linear correlation and a positive correlation in Guilin. Based on the good linear relationship between $T_{\mathrm{m}}$ and $T_{\mathrm{s}}$, the regression analysis method is used to calculate $T_{\mathrm{m}}$ values by Equation (2).

To find the optimal regression equation coefficients $a$ and $b$, the regression coefficient is obtained to minimize the sum of deviation squares between the sample values and the corresponding theoretical values according to the principle of least squares in statistics. The coefficients of the linear regression equation are calculated by using the Guilin radiosonde profiles in 2017 and divided them into 12 months, 4 seasons and the whole year. The Table 2 shows the regression coefficients $a, b, \mathrm{R}$ and the number of samples (n) used.

\begin{tabular}{cccccc}
\hline Seasons & Months & $a$ & $b$ & $\mathrm{R}$ & $\mathrm{n}$ \\
\hline \multirow{4}{*}{ Spring } & Mar & 80.389 & 0.695 & 0.785 & 61 \\
& Apr & 69.828 & 0.725 & 0.862 & 57 \\
& May & 119.919 & 0.556 & 0.768 & 62 \\
\hline \multirow{4}{*}{ Summer } & Jun & 99.128 & 0.625 & 0.873 & 60 \\
& Jul & 78.778 & 0.692 & 0.792 & 62 \\
& Aug & 174.202 & 0.374 & 0.607 & 62 \\
\hline \multirow{4}{*}{ Autumn } & Sep & 134.921 & 0.504 & 0.588 & 60 \\
& Oct & 118.016 & 0.561 & 0.557 & 62 \\
& Nov & 43.217 & 0.823 & 0.788 & 60 \\
\hline \multirow{4}{*}{ Winter } & Dec & 146.554 & 0.455 & 0.284 & 62 \\
& Jan & 109.521 & 0.586 & 0.605 & 62 \\
\hline Year & Feb & 78.18 & 0.698 & 0.724 & 53 \\
\hline Tate & & 97.388 & 0.631 & 0.895 & 723 \\
\hline
\end{tabular}

Table 2. Regression coefficients of atmospheric weighted average temperature in Guilin
The coefficient of regression equation can be used to the significance test. When the $\mathrm{R} \geqslant \gamma_{a}(f), \gamma_{a}(f)$ is the critical value of correlation coefficient, indicating the correlation coefficient can pass the significance test at the significancelevel of 0.01 , otherwise, it can't pass the significance test. When divided by month, the sample number is about 60 , and the degree of freedom $(f)$ is equal to $\mathrm{n}$ minus 2 . When the significance level equal to $0.01, \gamma_{a}(f)=0.325$. When divided by season or year, the sample number is greater than 100 , and $f=\mathrm{n}-2>100$. Taking the significance level equal to $0.01, \gamma_{a}(f)=0.254$.

The above statistics show that: firstly, for the regression equation coefficients of different months, the correlation coefficients are generally not high, but all can pass the significance test. For the months with low $\mathrm{R}$ values, such as in December, the $\mathrm{R}$ value is only 0.284 , but $\mathrm{R}$ value is greater than 0.5 for most months. Secondly, the correlation coefficient is best in spring, worst in winter, and slightly lower in summer and autumn when divided by different seasons. Thirdly, when the number of samples is small, the correlation is poor, and the correlation will increase with the increase of the number of samples. The correlation coefficient of the whole year reaches 0.8946 . Therefore, in order to improve the accuracy of retrieving PWV from the GNSS, the selection of meteorological data should not be too few. So, the regression equation coefficients of the $a$ and $b$ calculated throughout the whole year are put into the Equation (2), and the $T_{\mathrm{m}}$ model of Guilin is obtained as follows:

$$
T_{m}=97.3878+0.6312 T_{s}
$$

\subsection{Evaluation of Guilin $T_{\mathrm{m}}$ Model}

To analyze the new Guilin local $T_{\mathrm{m}}$ model (Guilin model), the Bevis model, Lijianguo model (LJ model) and Guilin model are used to calculate the $T_{\mathrm{m}}$ values according to the $T_{\mathrm{s}}$ of Guilin station in 2017 . The $T_{\mathrm{m}}$ values directly calculated by the numerical integration method are taken as the reference values and compared with the $T_{\mathrm{m}}$ values calculated by the three models respectively. The results are shown in Table 3 and Figure 3.

Table 3 shows the monthly comparative analysis parameters of 3 models. According to Table 3, the root mean square error (RMSE) and Standard Deviation (STD) of the Guilin model are smaller than Bevis model and LJ model, and the relative error is even close to 0 (possibly due to the small number of samples). Therefore, the accuracy of the Guilin model is obviously higher than Bevis model and LJ model. As can be seen from the Figure 3 , the $T_{\mathrm{m}}$ values calculated by the three models are consistent with the reference values on the whole. Compared with the Bevis model and LJ model, the $T_{\mathrm{m}}$ values calculated by the newly established Guilin model have good agreement with the reference values. In order to clearly compare the deviations between the $T_{\mathrm{m}}$ values of three models and the reference values, the scatter diagram of the difference between the calculated $T_{\mathrm{m}}$ values of the three models and the reference values is drawn as shown in Figure 4.

Bias values can be seen from Figure 4, the amplitude range of the bias between $T_{\mathrm{m}}$ values of the 3 models and reference values is basically within $\pm 10 \mathrm{~K}$, the $T_{\mathrm{m}}$ values calculated by Guilin 


\begin{tabular}{|c|c|c|c|c|c|c|c|}
\hline \multirow{2}{*}{ Months } & \multirow{2}{*}{$\begin{array}{l}\text { Reference } \\
\text { values }\end{array}$} & \multicolumn{2}{|c|}{ Bevis model } & \multicolumn{2}{|c|}{ LJ model } & \multicolumn{2}{|c|}{ Guilin model } \\
\hline & & $T_{\mathrm{m}}$ & Bias & $T_{\mathrm{m}}$ & Bias & $T_{\mathrm{m}}$ & Bias \\
\hline Jan & 275.78 & 274.317 & 1.463 & 273.681 & 2.099 & 276.33 & -0.55 \\
\hline Feb & 276.603 & 274.984 & 1.62 & 274.432 & 2.172 & 276.915 & -0.312 \\
\hline Mar & 279.911 & 276.979 & 2.932 & 276.676 & 3.235 & 278.664 & 1.247 \\
\hline Apr & 282.617 & 281.452 & 1.165 & 281.709 & 0.908 & 282.586 & 0.032 \\
\hline May & 285.22 & 284.192 & 1.028 & 284.791 & 0.429 & 284.988 & 0.233 \\
\hline Jun & 286.62 & 286.044 & 0.576 & 286.875 & -0.255 & 286.611 & 0.009 \\
\hline Jul & 286.491 & 286.285 & 0.206 & 287.145 & -0.655 & 286.822 & -0.331 \\
\hline Aug & 286.402 & 286.201 & 0.201 & 287.051 & -0.65 & 286.749 & -0.347 \\
\hline Sep & 285.449 & 285.132 & 0.317 & 285.849 & -0.399 & 285.812 & -0.362 \\
\hline Oct & 283.43 & 282.318 & 1.112 & 282.683 & 0.748 & 283.344 & 0.086 \\
\hline Nov & 280.447 & 277.822 & 2.625 & 277.624 & 2.823 & 279.403 & 1.044 \\
\hline Dec & 275.209 & 273.873 & 1.336 & 273.182 & 2.027 & 275.941 & -0.732 \\
\hline Average & 282.015 & 280.800 & 1.215 & 280.975 & 1.040 & 282.014 & 0.001 \\
\hline $\begin{array}{c}\text { Relative } \\
\text { Error }\end{array}$ & $0 \%$ & \multicolumn{2}{|c|}{$0.431 \%$} & \multicolumn{2}{|c|}{$0.369 \%$} & \multicolumn{2}{|c|}{$0.0006 \%$} \\
\hline STD & 0 & \multicolumn{2}{|c|}{5.364} & \multicolumn{2}{|c|}{6.034} & \multicolumn{2}{|c|}{4.702} \\
\hline RMSE & 0 & \multicolumn{2}{|c|}{2.723} & \multicolumn{2}{|c|}{2.889} & \multicolumn{2}{|c|}{2.349} \\
\hline $\mathrm{R}$ & 1 & \multicolumn{2}{|c|}{0.895} & \multicolumn{2}{|c|}{0.895} & \multicolumn{2}{|c|}{0.895} \\
\hline
\end{tabular}

Table 3. Comparison of $T_{\mathrm{m}}$ accuracy calculated by 3 models of Guilin station in 2017
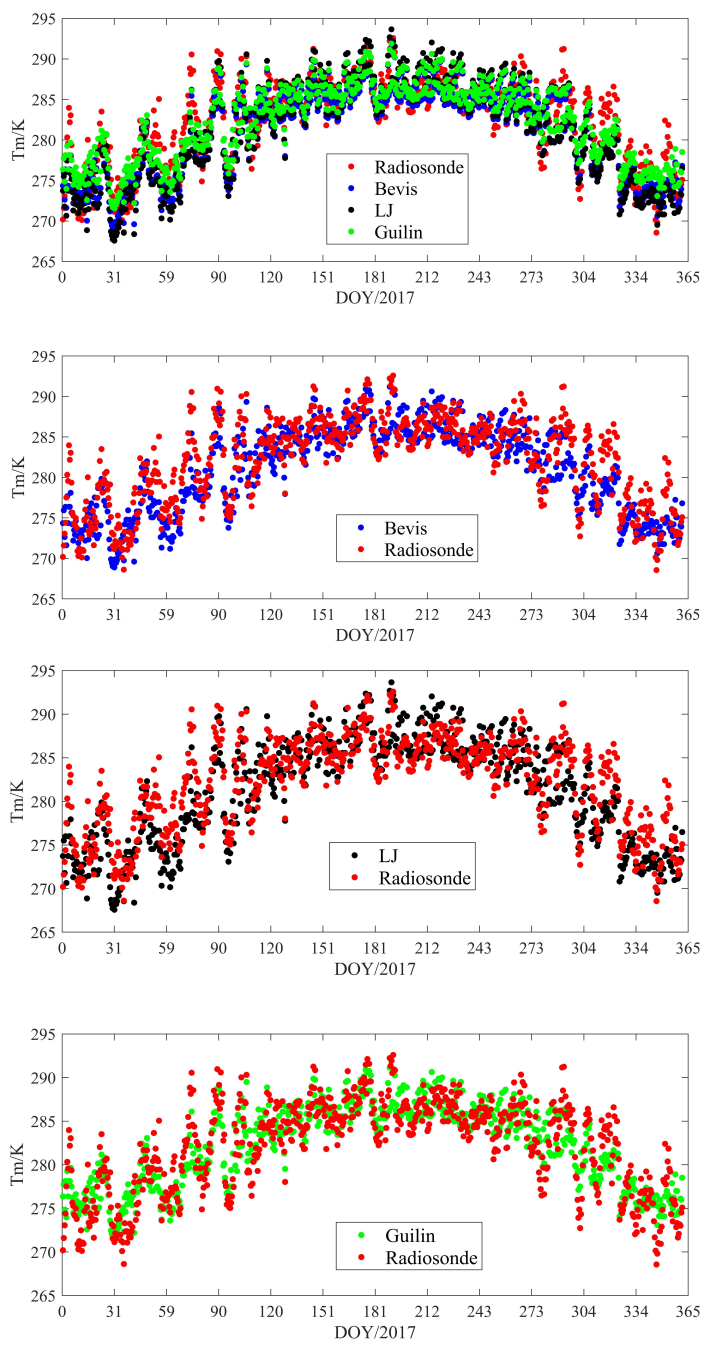

Figure 3. Comparison of $T_{\mathrm{m}}$ values of the 3 kinds of models and reference values
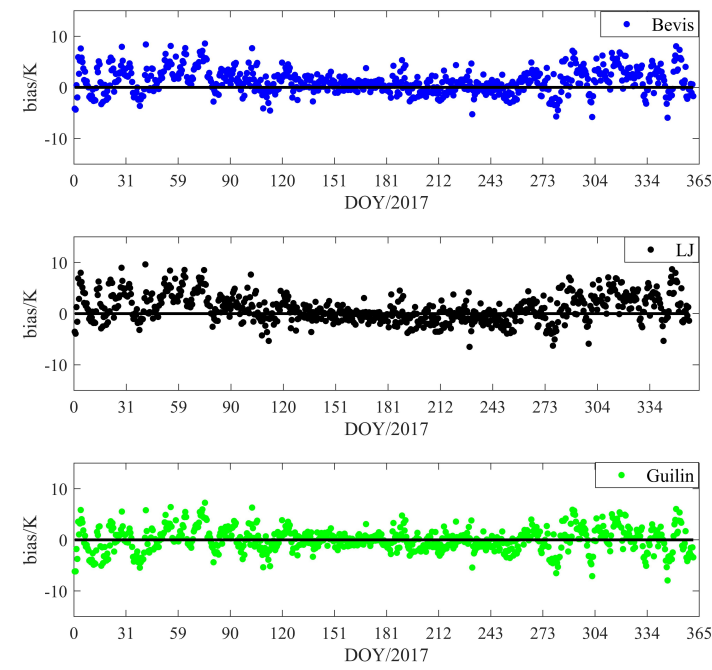

Figure 4. The bias between $T_{\mathrm{m}}$ values of the 3 kinds of models and reference values

model fluctuate around $0 \mathrm{~K}$, and volatility is relatively uniform throughout the whole year. However, the bias values of Bevis model and LJ model are slightly larger, especially in spring and winter, it fluctuates greatly, and most of the bias values are above 0 , which is a positive bias. Bevis model and $\mathrm{LJ}$ model are greatly influenced by the seasons. But, a few of $T_{\mathrm{m}}$ values calculated from the three models have a large deviation from the reference value especially in spring and winter, which may be caused by a large change of water vapor in a certain period, and the specific reasons need to be further studied. 
Bevis model and LJ model were respectively established by using the radiosonde profiles of various meteorological stations and stations in the mainland of the United States $\left(27 \sim 65^{\circ} \mathrm{N}\right.$ area) and the eastern China $\left(20 \sim 50^{\circ} \mathrm{N}, 100 \sim 130^{\circ} \mathrm{E}\right)$. Based on the above analysis conclusions, when the two models are used in Guilin, systematic errors of local models may be generated, so that the obtained values are not optimal. The models established in local areas are built by using local meteorological data. Compared with the Bevis model and LJ model, the models established in local areas have greater applicability, reliability and smaller errors. Therefore, the newly established localization model of Guilin is the best model with good performance and can be applied to the calculation of the $T_{\mathrm{m}}$ values in Guilin.

\subsection{Impact of $T_{\mathrm{m}}$ Model on GNSS-PWV}

The PWV retrieved from GNSS requires the support of $T_{\mathrm{m}}$ values with good accuracy. Most GNSS stations are mainly designed for space geodetic research without meteorological sensors. Moreover, GNSS stations and radiosonde stations are located at different locations, so it is difficult to conduct a comprehensive and global assessment of the impact of GNSSPWV. According to some previous studies (Wang et al., 2005; Huang et al., 2019), the influence of $T_{\mathrm{m}}$ values calculated by three different models on GNSS-PWV was analyzed theoretically. In this paper, a similar method is employed to analyze the impact of $T_{\mathrm{m}}$ on GNSS-PWV. The RMS between $T_{\mathrm{m}}$ and PWV can be calculated by the following:

$$
\begin{aligned}
\frac{\mathrm{RMS}_{\mathrm{pwv}}}{\mathrm{PWV}} & =\frac{\mathrm{RMS}_{\Pi}}{\Pi}=\frac{k_{3} \cdot \mathrm{RMS}_{T_{m}}}{\left(\frac{k_{3}}{T_{m}}+k_{2}^{\prime}\right) T_{m}^{2}} \\
& =\frac{k_{3}}{\left(\frac{k_{3}}{T_{m}}+k_{2}^{\prime}\right) T_{m}} \cdot \frac{\mathrm{RMS}_{T_{m}}}{T_{m}}
\end{aligned}
$$

Where $\mathrm{RMS}_{\mathrm{pwv}}$ is the error of PWV, $\mathrm{RMS}_{T_{m}}$ is the error of $T_{\mathrm{m}}$, which has been calculated from Sect.3.2, PWV is given by radiosonde profiles. $\mathrm{RMS}_{\mathrm{pwv}} / \mathrm{PWV}$ is defined as the relative error of PWV. $\mathrm{RMS}_{\mathrm{pwv}}$ and $\mathrm{RMS}_{\mathrm{pwv}} / \mathrm{PWV}$ are used to evaluate the impact of the errors in $T_{\mathrm{m}}$ on GNSS-PWV results. The calculation results of $\mathrm{RMS}_{\mathrm{pwv}}$ and $\mathrm{RMS}_{\mathrm{pwv}} / \mathrm{PWV}$ under different models are shown in Table 4.

\begin{tabular}{ccccccccc}
\hline & \multicolumn{3}{c}{$\mathrm{RMS}_{T_{m}}(\mathrm{~mm})$} & & \multicolumn{3}{c}{$\mathrm{RMS}_{\mathrm{pwv}} / \mathrm{PWV}(\%)$} \\
\cline { 2 - 3 } \cline { 7 - 8 } & Max & Min & Mean & & Max & Min & Mean \\
\hline Bevis & 0.67 & 0.07 & 0.39 & & 1.00 & 0.92 & 0.95 \\
LJ & 0.71 & 0.07 & 0.41 & & 1.06 & 0.97 & 1.01 \\
Guilin & 0.58 & 0.06 & 0.33 & & 0.85 & 0.79 & 0.82 \\
\hline
\end{tabular}

Table 4. The statistical results of errors and relative errors in PWV of 3 kinds of models

It can be seen from Table 4 that the annual mean values of $\mathrm{RMS}_{\mathrm{pwv}}$ obtained from Equation (11) of the three models both are small. According to $\mathrm{RMS}_{\mathrm{pwv}}$, the $\mathrm{RMS}_{\mathrm{pwv}}$ values of Guilin model are all less than $0.60 \mathrm{~mm}$, and the mean of $\mathrm{RMS}_{\mathrm{pwv}}$ value is $0.33 \mathrm{~mm}$. According to $\mathrm{RMS}_{\mathrm{pwv}} / \mathrm{PWV}$, the annual mean value of Guilin model is $0.82 \%$, ranging from $0.79 \%$ to $0.85 \%$. No matter the $\mathrm{RMS}_{\mathrm{pwv}}$ or $\mathrm{RMS}_{\mathrm{pwv}} / \mathrm{PWV}$, the calculation accuracy of Guilin model is better than the other two models. That is to say, the impact of $T_{\mathrm{m}}$ values calculated by Guilin model on calculated PWV is smaller comparing with the Bevis model and LJ model. Because the Guilin model is a regional model suitable for Guilin, which is specially established to calculate $T_{\mathrm{m}}$ values, the Guilin model can provide more accurate and realtime PWV values of GNSS in Guilin comparing with the other two models.

\section{CONCLUSIONS}

Variability and changes in water vapor is essential to study various climate patterns. Monitoring the climate change of the whole area in Guilin is limited due to insufficient observations. With the development of the ground-based GNSS over the last decade, such measurements have become important for measuring highly dynamic water vapor in the atmosphere. In this paper, for improving the calculated accuracy of PWV, a new $T_{\mathrm{m}}$ model suitable for Guilin is constructed using the observation data of Guilin radiosonde station in 2017, and the results show the new $T_{\mathrm{m}}$ model in Guilin has a relatively good performance comparing with the classical Bevis, LJ $T_{\mathrm{m}}$ models, which are improved by $14 \%$ and $19 \%$, respectively. A regional empirical $T_{\mathrm{m}}$ model is better adapted to the geographical and climatic characteristics in a specific region and it is still necessary for more accurate determinations.

Furthermore, the regional $T_{\mathrm{m}}$ model in Guilin can improve the accuracy of PWV calculation and accomplish real-time PWV estimate. It can serve the research work better for Guilin meteorology.

\section{ACKNOWLEDGEMENTS}

This work was sponsored by the National Natural Foundation of China (41664002; 41704027); Guangxi Natural Science Foundation of China (2018GXNSFAA294045; 2017GXNSFD A198016; 2017GXNSFBA198139); the "Ba Gui Scholars" program of the provincial government of Guangxi; and the Guangxi Key Laboratory of Spatial Information and Geomatics (14-045-24-10;16-380-25-01). The authors acknowledge the University of Wyoming for providing radiosonde profiles.

\section{REFERENCES}

Askne J., Nordius H, 1987: Estimation of Tropospheric Delay for Microwaves from Surface Weather Data. Radio Sci. 22 (3), 379-386.

Bokoye, A.I., Royer, A., O'Neill, N.T., et al., 2003: Multisensor Analysis of Integrated Atmospheric Water Vapor over Canada and Alaska, J. Journal of Geophysical Reseach: Atmospheric. 108 (4480), D15. http://dx.doi.org/10.1029/2002JD002721.

Bevis M,Businger S., Herring T.A., et al, 1992: GPS Meteorology: Remote Sensing of Atmospheric Water Vapor Using the Global Positioning System. Journal of Geophysics Research. 97 (D14), 15787-15801.

Bolton D, 1980: The Computation of Equivalent Potential Temperature. Monthly Weather Review. 108, 1046-1053.

Elgered, G., Johansson, J.M., Rönnäng, B.O., Davis, J.L., 1997: Measuring Regional Atmospheric Water Vapor Using the Swedish Permanent GPS Network, Geophysical Research Letters. 24, 2663-2666. 
Emardson, T.R., Elgered, G., Johannson, J.M., 1998: Three Months of Continuous Monitoring of Atmospheric Water Vapor with a Network of Global Positioning System Receivers, Journal of Geophysical Reseach: Atmospheric. 103, 1807-1820.

Hernández-Pajares, M., Juan, J.M., Sanz, J., Colombo, O.L., van der Marel, H., 2001: A New Strategy for Real-Time Integrated Water Vapor Determination in WADGPS Networks, Geophysical Research Letters. 28, 3267-3270.

Huang Liangke, Jiang Weiping, Liu Lilong, et al., 2019: A New Global Grid Model for the Determination of Atmospheric Weighted Mean Temperature in GPS Precipitable Water Vapor, Journal of Geodesy. 93, 159-176. https://doi.org/10.1007/s001 90-018-1148-9.

Li Guoping, 2014: Ground-Based GPS Meteorology. Science Press, Beijing. (in Chinese)

Li Jianguo, Mao Jietai, Li Chengcai, 1999: The Approach to Remote Sensing of Water Vapor Based on GPS and Linear Regression $T_{\mathrm{m}}$ in Eastern Region of China, Acta Meteorologica Sinica. 57 (3), 283-292. (in Chinese)

Liu Lilong, Yao Chaolong, Wen Hongyan, 2012: Empirical $T_{\mathrm{m}}$ Modeling in the Region of Guangxi, Geodesy and Geodynamics. $3(4), 47-52$.

Vaquero-Martínez, J., Antón, M., de Galisteo, J.P.O., et al., 2017: Validation of Itegrated Water Vapor from OMI Satellite Instrument Against Reference GPS Data at the Iberian Peninsula, Science Total Environment. 580, 857-864.

Wang XM, Zhang KF, Wu SQ, Fan SJ, Cheng YY, 2016: Water Vapor Weighted Mean Temperature and its Impact on the Determination of Precipitable Water Vapor and its Linear Trend, Journal of Geophysical Reseach: Atmospheric. 121, 833-852.

Wang JH, Zhang LY, Dai AG, 2005: Global Estimates of Water-Vapor Weighted Mean Temperature of the Atmosphere for GPS Applications, Journal of Geophysical Research Atmospheres. https://doi.org/10.1029/2005JD006215.

Xie Shaofeng, Jin Liyang, Wang Xinqiao, et al., 2017: Atmospheric Weighted Mean Temperature Model in Guangxi, Science Technology and Engineering. 17 (12), 133-137. (in Chinese) 